\title{
Correction to: The novel insight into anti-inflammatory and anxiolytic effects of psychobiotics in diabetic rats: possible link between gut microbiota and brain regions
}

\author{
Elaheh-Sadat Hosseinifard ${ }^{1,3} \cdot$ Maryam Saghafi-Asl $^{2,3,4} \cdot$ Khadijeh Bavafa-Valenlia $^{1,3} \cdot$ Mohammad Morshedi $^{1,2,3}$
}

Published online: 6 September 2019

(c) Springer-Verlag GmbH Germany, part of Springer Nature 2019

\section{Correction to: European Journal of Nutrition}

https://doi.org/10.1007/s00394-019-01924-7

The original version of this article unfortunately contained a mistake in the order of the author list.

Please find the corrected author list here: Elaheh-Sadat Hosseinifard, Maryam Saghafi-Asl, Khadijeh Bavafa-Valenlia, Mohammad Morshedi

Please note that Dr. Maryam Saghafi-Asl (saghafiaslm@ gmail.com) is corresponding author of this publication, while Mohammad Morshedi (Md.morshedi@yahoo.com) is co-corresponding author.

The original article can be found online at https://doi.org/10.1007/ s00394-019-01924-7.

Maryam Saghafi-Asl

saghafiaslm@gmail.com

Mohammad Morshedi

Md.morshedi@yahoo.com

1 Student Research Committee, Tabriz University of Medical Sciences, Tabriz, Iran

2 Drug Applied Research Center, Tabriz University of Medical Sciences, Tabriz, Iran

3 Nutrition Research Center, School of Nutrition and Food Sciences, Tabriz University of Medical Sciences, Tabriz, Iran

4 Department of Clinical Nutrition, School of Nutrition and Food Sciences, Tabriz University of Medical Sciences, Tabriz, Iran 